\title{
Clinical and Functional Dynamics of Physical Working Capacity and Psychological Adaptation in Patients with Acute Coronary Syndrome at the Stages of Rehabilitation
}

\author{
Roksolana Nesterak ${ }^{* 1}$, Sofia Bardashevska²
}

\begin{abstract}
The objective of the research was to analyze the effectiveness of using suggestive therapy in the patients with acute coronary syndrome by assessing the dynamics of the clinical condition and indicators of anxiety.

Materials and Methods. There were examined 135 patients with non-ST-segment elevation myocardial infarction, 60 patients with the use of the conservative treatment and 75 patients who underwent percutaneous coronary intervention. The dynamics of objective indices, adaptation changes and anxiety indices in the groups of patients with traditional treatment and in the groups of patients with suggestive therapy in addition to the traditional rehabilitation measures, were analyzed.

Results. Analyzing the dynamics of adaptive indices, it was determined that in the group of patients with non-ST-segment elevation myocardial infarction, who were performed conservative therapy, the dynamics was less significant, which is related to the general desadaptative syndrome. Changes in the group of patients undergoing percutaneous coronary intervention and suggestive therapy, with a decrease of blood pressure, heart rate, and a decrease in the index of functional changes from $3.78 \pm 0.15$ points before the intervention up to $2.92 \pm 0.13$ points after suggestive therapy $(p<0.01)$ were more significant. In all groups of patients, high levels of reactive anxiety were observed at the beginning of treatment. As a result of treatment, a decrease in anxiety was noted, but more pronounced changes were seen in the group with the use of suggestive therapy $(p<0.05)$.

Conclusions. The use of suggestive therapy methods when treating the patients with acute coronary syndrome is an important intervention, that provides a comprehensive approach considering all the components, enhances the patients' adaptive abilities in the rehabilitation phase, improves the quality and effectiveness of restorative treatment. The use of suggestive therapy at the rehabilitation stage improves the clinical course, reduces anginal manifestations, stabilizes blood pressure and increases exercise tolerance.
\end{abstract}

Keywords

ischemic heart disease; rehabilitation; adaptation; psychology; anxiety

${ }^{1}$ Ivano-Frankivsk National Medical University, Ivano-Frankivsk, Ukraine

2Ivano-Frankivsk Regional Clinical Center of Cardiology, Ivano-Frankivsk, Ukraine

*Corresponding author: roxolana.nesterak@gmail.com

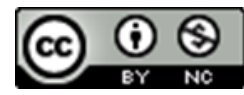

Copyright (C)Roksolana Nesterak, Sofia Bardashevska, 2019

\section{Problem statement and analysis of the latest research}

Desadaptative strategies as for the behavior of patients which develop on the background of a chronic disease such a coronary heart disease (CHD) can significantly reduce patients' attitude toward the favour to treatment and fulfillment of the medical prescriptions, that further exacerbates the course of the disease. 


\section{Clinical and Functional Dynamics of Physical Working Capacity and Psychological Adaptation in Patients with Acute Coronary Syndrome at the Stages of Rehabilitation - 2/6}

The destabilization of a chronic disease, cardiogenic life-threatening conditions associated with a vital threat, alter the system of personality attitude thereby worsening mental adaptation under new conditions. Such changes may manifest themselves in the form of non-implementation of medical recommendations, anxiety-depressive disorders, worsening of the clinical condition [1].

Mental adaptation is considered as a systemic process that involves the reorganization of the system of personal relation in order to achieve a balance between the necessity of the personality and the new conditions of life. Mental adaptation under the conditions of the disease combines the emotional and the behavioral components. These components are independent ones; the emotional aspect is predominantly internal, subjective, and the behavioral one is external, objective (as the degree of conformity of behavior to a particular image) [2].

The achievement of the positive dynamics in treatment of the patients with CHD is possible in close collaboration with the attending physician, rehabilitation physician, psychologist and the patient himself. The criterion for the effectiveness of cooperation is the patients' favour to the treatment; its provision is possible if the level of situational and personal anxiety decreases, and the competence in the nature of the disease, causal relationships of behavior and symptom, the potential prospects of recovery, etc. increases. Therefore, it is important to develop additional measures to reduce anxiety and increase the patients' competence in the scope of their own health, which would be an effective factor of the improvement of the quality and effectiveness of restorative treatment $[3,4,5]$.

Suggestive therapy is the method of achievement of a state of comfortable relaxation by the patient, which helps reduce the level of situational and personal anxiety, congruent self-perception, illness and current state of health $[6,7]$.

Musical accompaniment is used to increase suggestion efficiency. The mechanism of music action onto the cardiovascular system is the creation of an appropriate psycho-emotional background and influence through the autonomic nervous system. Calm, slow-paced music enhances the tone of the parasympathetic compartment, which slows the heart rate (HR) and lowers blood pressure (BP). The use of music therapy reduces the severity of anxiety and improves the quality of sleep. The study of the influence of music on the course of stress showed that the levels of biochemical markers of stress (noradrenaline, adrenocorticotropic hormone, cortisol, leptin, carbon dioxide) reduce simultaneously with the restoration of a positive emotional state against the background of music intervention, and daily listening to the positive music significantly lessens the influence of chronic stress $[8,9,10]$.

The objective indices of the condition of the cardiovascular system are BP and HR. These indices can be considered as adaptation to changes in the disease, as well as a criterion for the effectiveness of therapeutic and rehabilitation interventions [11].

The objective of the research was to analyze the effectiveness of using suggestive therapy in the patients with acute coronary syndrome by assessing the dynamics of the clinical condition and indices of anxiety.

\section{Materials and Methods}

There were examined 135 patients with non-STsegment elevation myocardial infarction (NSTEMI), 60 patients with conservative treatment, respectively, and 75 patients with invasive treatment percutaneous coronary intervention (PCI). We have analyzed the dynamics of objective indices, adaptation changes and anxiety indices in the groups of patients with traditional treatment and in the groups of patients where, along with traditional rehabilitation measures, a psychological component - suggestive therapy, was used. All patients received standard therapy for $\mathrm{CHD}$, depending on the form of CHD and in accordance with the recommendations of the Working Groups of the European and Ukrainian Societies.

The use of suggestive therapy was performed in the departments of the Regional Clinical Center of Cardiology. Classes were held every day (the number of lessons was 21); lessons were held in the wards of the department, from 3 to 9 people participated in each class; duration of the lesson 


\section{Clinical and Functional Dynamics of Physical Working Capacity and Psychological Adaptation in Patients with Acute Coronary Syndrome at the Stages of Rehabilitation - 3/6}

was 20 minutes; during the class, the data were recorded in a developed observation form.

There was evaluated the clinical course on the basis of complaints, subjective and objective indices. HR, BP and the index of functional changes (IFC) were determined before the performance of suggestive therapy and after the intervention. The adaptation potential (AP) was analyzed according to the quantitative index (RM Baievskyi, AP Berseneva) such as the IFC or the level of adaptation, which allows evaluating the adaptive reactions of the organism as a manifestation of different stages of general adaptation syndrome $[12,13]$.

$A P($ points $)=0.011 \times(H R)+0.014 \times(S B P)+$ $+0.008 \times(D B P)+0.014 \times($ age, years $)+0.009 \times$ $\times($ bodyweight, $\mathrm{kg})-0.009 \times($ height, $\mathrm{cm})-0.27$.

Anxiety level was assessed by the following questionnaires - the Spielberg-Hanin Situational and Personal Anxiety Scale and the Seattle Angina Questionnaire (SAQ).

Statistical processing was performed using software "Microsoft Excel" and "Statistica" v. 10.0 StatSoft, USA. The results were subjected to statistical processing by the methods of variational statistics (arithmetic mean value, standard error, standard deviation, confidence interval). The probability of differences between the comparison groups was determined using Student's parametric criterion. Statistical testing of hypotheses to determine differences between nonparametric signs was performed using the $\chi^{2}$-criterion and the $\mathrm{z}$-criterion. Results with $\mathrm{p}<0.05$ were considered statistically significant.

\section{Results}

The average age of the patients with NSTEMI who underwent conservative treatment tactics, was $68.38 \pm 1.30$ years, and in the group of the patients who were performed PCI, it was $64.70 \pm 1.65$ years.

Among the studied patients with NSTEMI, who were performed conservative treatment, $63.3 \%$ (38) were city residents, $36.7 \%$ were village residents; accordingly, stenting was performed in $68.0 \%$ and $32.0 \%$ of the patients.

Analyzing the dynamics of adaptation indica- tors according to the level of the IFC, BP, HR, it was found that in the group of the patients with NSTEMI, who were performed conservative therapy, the dynamics was less significant, due to general desadaptative syndrome, the presence of risk factors and the used treatment method (Table 1).

Table 1. Dynamics of adaptation indices in patients with nstemi who were performed conservative therapy.

\begin{tabular}{lcc}
\hline Indices & $\begin{array}{c}\text { Before } \\
\text { Intervention }\end{array}$ & $\begin{array}{c}\text { After } \\
\text { Intervention }\end{array}$ \\
\hline HR, min. & $84.3 \pm 3.32$ & $76.6 \pm 3.30$ \\
SAP, mm Hg & $150.0 \pm 3.12$ & $138.6 \pm 3.10^{*}$ \\
DAP, mm Hg & $92.3 \pm 3.24$ & $88.2 \pm 3.20$ \\
IFC, points & $3.82 \pm 0.12$ & $3.18 \pm 0.11$ \\
\hline
\end{tabular}

Notes: significance of difference of the indices in comparison with vthe alues before intervention: $*<0.05 ; * *<0.01$

$\mathrm{SAP}$ - systolic arterial pressure; DAP - diastolic arterial pressure.

Analyzing the dynamics of indices of adaptation components, the decrease in BP and HR in the use of suggestive methods of therapy were determined. A decrease in the IFC was found, which indicates a decrease in the adaptation index and an improvement of the processes of adaptation of the organism (Table 2).

Table 2. Dynamics of adaptation indices in patients with nstemi who were treated using invasive tactics.

\begin{tabular}{lcc}
\hline Indices & $\begin{array}{c}\text { Before } \\
\text { Intervention }\end{array}$ & $\begin{array}{c}\text { After } \\
\text { Intervention }\end{array}$ \\
\hline HR, min. & $80.2 \pm 3.40$ & $62.7 \pm 3.32^{* *}$ \\
SAP, mm Hg & $148.5 \pm 3.16$ & $126.6 \pm 3.14 * *$ \\
DAP, mm Hg & $90.8 \pm 3.26$ & $68.5 \pm 3.25$ \\
IFC, points & $3.78 \pm 0.15$ & $2.92 \pm 0.13^{* *}$ \\
\hline
\end{tabular}

Notes: significance of difference of the indices in comparison with the values before intervention: $*<0.05 ; * *<0.01$.

The dynamics of reactive and personal anxiety 


\section{Clinical and Functional Dynamics of Physical Working Capacity and Psychological Adaptation in Patients with Acute Coronary Syndrome at the Stages of Rehabilitation - 4/6}

indices according to the Spielberg-Hanin questionnaire in the patients with NSTEMI in the application of traditional rehabilitation and in combination with suggestive therapy, was analyzed.

It was determined, that at the beginning of treatment in the patients with NSTEMI, who were performed conservative treatment, high levels of reactive anxiety were observed in all groups, in particular in the group of traditional treatment $(46.8 \pm 1.20)$ points, in the group of suggestive therapy use $-(47.2 \pm 1.19)$ points.

A month later, the decrease in reactive anxiety level was noted in suggestive therapy group, with no other changes observed in other groups $(\mathrm{p}>0.05)$. When analyzing personal anxiety as a more stable individual characteristic at the beginning of treatment, high levels were observed in all groups, (47.4 \pm 119$)$ points, $(48.5 \pm 1.20)$ points, respectively. In the group with the use of traditional methods of rehabilitation, there was no significant decrease in personal anxiety during hospital stay $(\mathrm{p}>0.05)$, and 6 months after treatment, the index was $(45.2 \pm 1.16)$ points.

In the group of the patients with NSTEMI, who underwent invasive treatment tactics, high levels of both reactive and personal anxiety were noted at the beginning of treatment. As a result of treatment, there was a decrease in anxiety; however, more pronounced changes were observed in the group with the use of suggestive therapy $(\mathrm{p}<0.05)$. A month later, the decrease in reactive anxiety levels was observed in the group of suggestive therapy - (37.7 \pm 1.18$)$ points; the level of personal anxiety was $(42.0 \pm 1.20)$ points, respectively $(\mathrm{p}<0.01)$ (Fig. 1).

\section{Discussion}

In order to improve restorative treatment and the efficiency of the patients' rehabilitation, we offer to use the method of suggestive therapy accompanied by music in traditional rehabilitation $[14,15]$.

Suggestion as a means of mental transformation of the patient's condition through relaxation and mastering the self-control skills of the body provides an opportunity to change the inner pic-

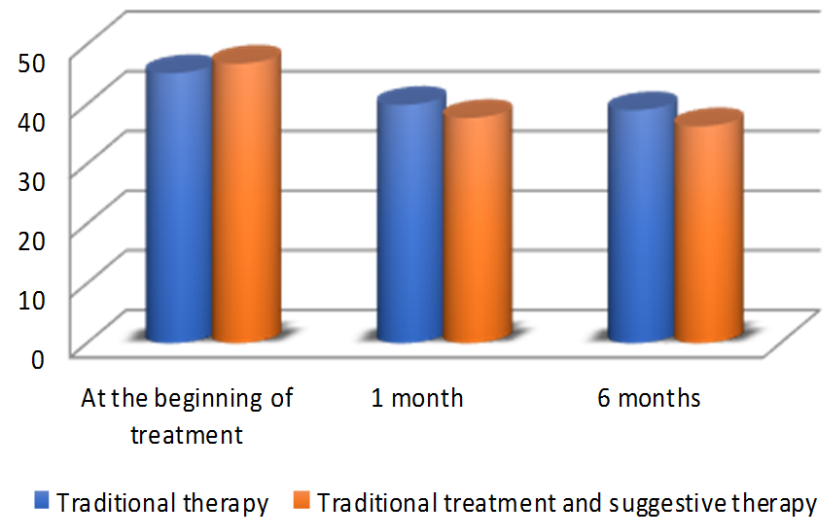

Figure 1. Level of reactive anxiety in the patients with NSTEMI, who underwent invasive treatment.

ture of the patient's world gradually, and under the managed conditions even to transform it quickly enough. Verbal suggestion involved in these transformational processes, along with other background effects of music, is particularly effective.

Suggestion acts through an audio channel, carrying certain verbal formulas aimed at accumulating and transforming the perception of information important for the patient. The content has a verbal embodiment that is repeatedly supported and duplicated by verbal formulas, inspired images, sound, ritual actions, etc. Such method of achieving a comfortable state by the patient is available and effective in a hospital setting.

During the use of the method of suggestive therapy with music accompaniment, the complex of diagnostic methods, both clinical and psychometric ones, is used; the clinical condition and objective indices (measurement of BP, HR, adaptive potential) are evaluated; psychometric indicators are tested; the psycho-emotional state, the levels of anxiety, depression, situational and personal anxiety are assessed.

The assessment of the body's adaptive resources in the patients with CHD is a multicomponent characteristic of patient's functional abilities. It is advisable to determine the adaptation potential in order to determine the peculiarities of the circulatory system functioning, the patient's adaptive abilities at the stages of rehabilitation, prognosis of the disease, as 
well as to monitor the effectiveness of the measures performed.

\section{Conclusions}

The use of suggestive therapy methods when treating the patients with acute coronary syndrome is an important intervention, that provides a comprehensive approach considering all the components, enhances the patients' adaptive abilities in the rehabilitation phase, improves the quality and effectiveness of rehabilitation.

In the process of rehabilitation, the use of suggestive therapy improves the clinical course, reduces anginal manifestations, stabilizes BP and increases exercise tolerance.

The patients who attended classes during the rehabilitation period, had better control of their bodies and improved well-being. They were able to differentiate emotions, reported feeling of lightness, fullness of energy, sleep normalization, the decrease in the level of situational anxiety. The patients became more optimistic as for the prospects of treatment; the social climate in the ward improved; trust in a doctor and treatment process increased.

\section{Prospects of Further Researches}

The evaluation of adaptation peculiarities in the patients after cardiosurgical interventions with the development of rehabilitation programs is of scientific and practical interest.

\section{References}

[1] Trifonova EA, Chernorai AV, Chumakova IO. The role of attitude to the disease in cardiac patients undergoing vital threat in the formation of the prediction of their mental adaptation to post-hospital period. Psychological Science and Education. 2014;6(4):157-168. [published in Russian] DOI: https://doi.org/10. 17759/psyedu.2014060414
[2] Berezin FB. Psikhologicheskaya i psikhofiziologicheskaya adaptatsiya cheloveka. Leningrad: Nauka; c1988. 270p.

[3] Bondar VP, Borisova IS, Nechuy-Veter LP. Opportunities for improving the rehabilitation of persons with disabilities of cardiological profile: Mission of psychologist. Visnyk VDNZU "Ukraiinska medychna stomatolohichna akademiia". 2018;18(61):14-17. [published in Ukrainian]

[4] Pogosova N, Saner H, Pedersen S et al. Psychosocial aspects in cardiac rehabilitation: From theory to practice. A position paper from the Cardiac Rehabilitation Section of the European Association of Cardiovascular Prevention and Rehabilitation of the European Society of Cardiology. Eur J Prev Cardiol. 2015;22(10):1290306. DOI: https://doi .org/10.1177/ 2047487314543075 [PMid:25059929]

[5] Mampuya WM. Cardiac rehabilitation past, present and future: an overview. Cardiovasc Diagn Ther. 2012 ;2(1):38-49.

[6] Aleksandrov AA. Autotrening: Autogennaya trenirovka. Meditatsiya. Relaksatsiya. Samogipnoz. St. Petersburg: Piter; c2011. 240p.

[7] Kocharyan GS. Autogennaya trenirovka. Zdorovye muzhchiny. 2011;4:32-39.

[8] Apanasenko GL, Savelyeva-Kulik NA. Music therapy: past, present and prospects of the development. Ukrainian Medical Journal. 2012;4:170-173. [published in Russian]

[9] Moroz HZ, Besklinska OZ, Druzi OV, Chernenko IO. Muzykoterapiia - vid davnyny do sohodennia. Therapia. Ukraiinskyi medychnyi visnyk. 2016;5:60-64.

[10] Berezutsky VI, Berezutskaya MS. The possibilities of musical therapy in treatment of arterial hypertension. Ukrainian Journal of Cardiology. 2017;5:105-111. [published in Russian] 
[11] Naumenko LYu. Osnovy medyko-sotsialnoii ekspertyzy i reabilitatsii khvorykh ta invalidiv: navchalno-metodychnyi posibnyk. Dnipro. c2017. 336p.

[12] Baevskiy RM, Berseneva AP. Otsenka adaptatsionnykh vozmozhnostey organizma i risk razvitiya zabolevaniy. Moscow: Meditsina; c1997. 235p.

[13] Zemlyanskaya NA, Yashchenko SG. Adaptational potential and its correction in patients with essential hypertension on the stage of sanatorium-resort rehabilitation. Ukraiinskyi medychnyi almanakh. 2011;4(14):49-52. [published in Russian]

[14] Nesterak RV. The role of suggestive therapy in rehabilitation treatment of patients after acute coronary syndrome. Art of Medicine 2019;1(9):89-95. [published in Ukrainian]

[15] Hasiuk MB, Nesterak RV. Metod suhestyvnoii terapii u reabilitatsii khvorykh $\mathrm{z}$ ishemichnoiu khvoroboiu sertsia ta infarktu miokarda $\mathrm{v}$ umovakh statsionaru. Psychology and Society. 2019;1(75):101-108.

Received: 2019-08-13

Revised: 2019-08-16

Accepted: 2019-08-29 